\title{
Otto Neurath e o legado do ISOTYPE
}

\author{
Design de Informação, Infografia, Pictogramas
}

\begin{abstract}
O trabalho de Otto Neurath (1882-1945) e sua equipe, através do ISOTYPE (International System of TYpographic Picture Education), influenciaram profundamente o design de informação. Nesse artigo procuro descrever a trajetória de eventos que levaram Neurath a criar o ISOTYPE, para poder analisar o legado do ISOTYPE nos pictogramas e na infografia jornalística. Esse legado não se limitou à Europa e EUA, isso é demonstrado através de exemplos da influencia do ISOTYPE no Brasil.
\end{abstract}

Information design, Infographics, Pictograms

The work of Otto Neurath (1882-1945) and his team, through ISOTYPE (International System of TYpographic Picture Education) deeply influenced information design. In this article I attempt do describe the course of events that led Neurath to create ISOTYPE, and then analyze the legacy of ISOTYPE in pictograms and infographics in journalism. This legacy was not limited to Europe and USA and this is shown through examples of the influence of ISOTYPE in Brazil.

\section{Introdução}

No começo do Século XX, o cientista social Otto Neurath (1882-1945) desenvolveu, com sua equipe, um tipo de sistema de linguagem pictórica chamada ISOTYPE (International System of TYpographic Picture Education) que teve grande influência sobre a forma como se projeta informação visualmente nos dias de hoje.

Nos anos de 1920, Jan Tschichold e a Nova Tipografia revolucionaram o moderno design gráfico, criando novos padrões de diagramação para indústria gráfica. Na mesma época, Otto Neurath iniciou suas experiências no âmbito da linguagem pictórica. Segundo Michael Twyman, em The Significance of ISOTYPE (1980), Otto Neurath é um dos pioneiros do moderno design gráfico, pois o ISOTYPE fez para a linguagem pictórica o que a Nova Tipografia fez para a linguagem verbal. Ou seja, Tschichold atualizou a tipografia para as necessidades do mundo moderno, enquanto Otto Neurath, e sua equipe, modernizaram a representação pictórica.

O ISOTYPE teve grande repercussão em sua época e influenciou a linguagem pictórica das gerações seguintes. No entanto, Neurath deixa claro em seus escritos que não pretendeu criar uma linguagem pictórica universal que substituisse a representação tipográfica da linguagem falada. Neurath considerava o ISOTYPE uma linguagem adicional. Para ele certas coisas não poderiam ser ditas apenas com palavras, com o auxílio da linguagem pictórica essas preposições poderiam ser configuradas com mais clareza (TWYMAN, 1980).

Este artigo pretende mostrar que as idéias modernistas, propostas no ISOTYPE, têm sido adaptadas aos novos contextos do design contemporâneo. Embora isso seja especialmente claro quando observamos a forma dos pictogramas, o sistema do ISOTYPE foi criado para a educação de leigos através de um sistema de linguagem pictórica própria. Portanto, a infografia e o uso dos diagramas se aproximam, em muitos aspectos, do projeto inicial de Neurath. Finalmente, Neurath propôs uma divisão de trabalho e, um método de pesquisa e projeto gráfico envolvendo um profissional responsável pela "transformação" da informação. Esse tipo de profissional se reflete especialmente na forma como o design da informação encara o problema da informação, valorizando o designer como criador de "conteúdo" e não apenas da "forma".

\section{Otto Neurath e o Círculo de Viena}

O aust ríaco Otto Neu rath (1882 -1945) foi um dos fundado res do po sitivismo lógico. Esse movimento, criado pelo chamado Círculo de Viena - um grupo de filósofos encabeçado por Moritz 
Schlic qu e se reunia ent re o s a nos de 1920 e 1930 - valo rizava o empirismo na ci ência e pretendia ex purgar a s tendên cias me tafísicas, ap urando o mé todo do co nhecimento e mpírico utilizando-se da lógica e da lingüística.

O Círculo de Viena analisava a linguagem através da lógica simbólica de Gottlob Frege, em um processo de valorização de sistemas abstratos que espelhariam a própria natureza. Essa idéia de lingüística compatível com a realidade da física, proposta pelo positivismo lógico, era contrastante com a da se miologia, de Ferdinand de Saussure, que defendia que a linguagem é formada por signos arbitrários que não precisam ser condizentes com a natureza (LUPTON, 1984).

Otto Neurath foi um dos membro $s \mathrm{~m}$ ais ra dicais do po sitivismo lógico e esteve envolvi do ativamente no ambicioso projeto da Enciclopédia das Ciências Unificadas. O projeto da unificação das ciências preten dia e ncontrar um a ba se teó rica comum e ntres as diversas ciências. $\mathrm{N}$ o entanto, e sse proj eto rev elava um ide al red ucionista que valo rizava a objetiv idade das ciências exatas, espe cialmente da física. Ne sse sentido, a matemática d a física teri a a objetividade ideal para ser o padrão de um conhecimento universal. Para Neurath, que era so ciólogo e economista, as ciências sociais precisavam alcançar um padrão maior de objetividade para se equipararem às ciências exatas. Para Neurath ainda, o ISOTYPE estava di retamente relacionado ao projeto da Enciclopédia das Ciências Unificadas. O sistema ISOTYPE seria a form a de comunicar, para um público não especializado, os conceitos complexos das ciências.

\section{ISOTYPE}

No final $d$ a Primeira Gu erra M undial, Neu rath foi a pontado co mo diretor do novo Mu seu de Economia de Guerra em Leipzig, em Viena. Co m o objetivo d e edu car co m maior clareza a população sobre questões econômicas, Neurath iniciou uma experiência com informação pictórica utilizando-se de textos, diagramas e ta belas estatísticas. Essa experiência com linguagem visual no Museu seria a base para seu trabalho posterior.

Depois de u m pe ríodo d e revolu ções em Vi ena, culminando no fim da monarquia e $\mathrm{n}$ o nascimento da Re pública da Bavária, oco rre o fechamento do Museu de E conomia de Guerra. Essas mudanças políticas levam Neurath, que já se encontrava filiado ao partido social democrata, a ficar cada vez mais ambicioso em seus projetos de mudança social. No entanto, seus planos são interrompidos com o colap so da República da Bavá ria, o que leva Neurath a passar um período curto na prisão. Todavia, logo que os sociais democratas adquirem o p oder em 1919, inicia-se a chamada fase da "Viena Vermelha". Neste momento, um programa do governo de reforma social, baseado em educação, é i nstituído em Viena e Neu rath é nome ado Secretário Geral do Instituto de Economia Social, onde se dedica a uma importante cooperativa habitacional.

Em 1924 Ne urath propõe a criação d o Mu seu de Economia e Sociedade, retomando suas pesquisas em educação visual. Nesse momento ele inicia, de fato, o desenvolvimento de um uma linguagem pictórica para a sociedade, chamada então de "método vienense", que mais tarde seria conhecida como ISOTYPE (CARTWRIGHT, 1996). Os primeiros gráficos começam a ser expostos no ano seguinte. Na medi da em que o material é $m$ ostrado além do âmbito d e Viena, com eça a receber uma aceitação entusiástica e o projeto se revela um sucesso internacional. Nesta mesma época a Ale manha está vivendo uma revolução no mundo do design e da t ipografia e Neurath , mesmo sem um treinam ento artístico, se mostra ex tremamente intere ssado. Ao longo do s anos ele conhece a equipe da Bauhaus, El Lissitzky, e recebe a colaboração de Jan Tschichold. Esta última ocorre por um b reve período, na época em q ue estava se preparando o Gesellschaft und Wirtschaft, Sociedade e Economia, um atlas de gráficos estatísticos publicado em Leipzig em 1930 (TWYMAN, 1980).

Em 1928 Neurath convida o artista plástico e gravador comunista Gerd Arntz para trabalhar em tempo integ ral no mu seu. Gerd Arntz teve um pap el importa nte por cria r, so b a orie ntação de Neurath, as representações figurativas do ISOTYPE elementos essenciais do $s$ istema. Neurath tinha visto uma exposição de gravuras de Gerd Arntz em Düsseldorf, e m 1926, e id entificou ali o potencial qu e o desenh o altamente sintético de Arntz tinh a pa ra ser apli cado no de sign do s símbolos. 

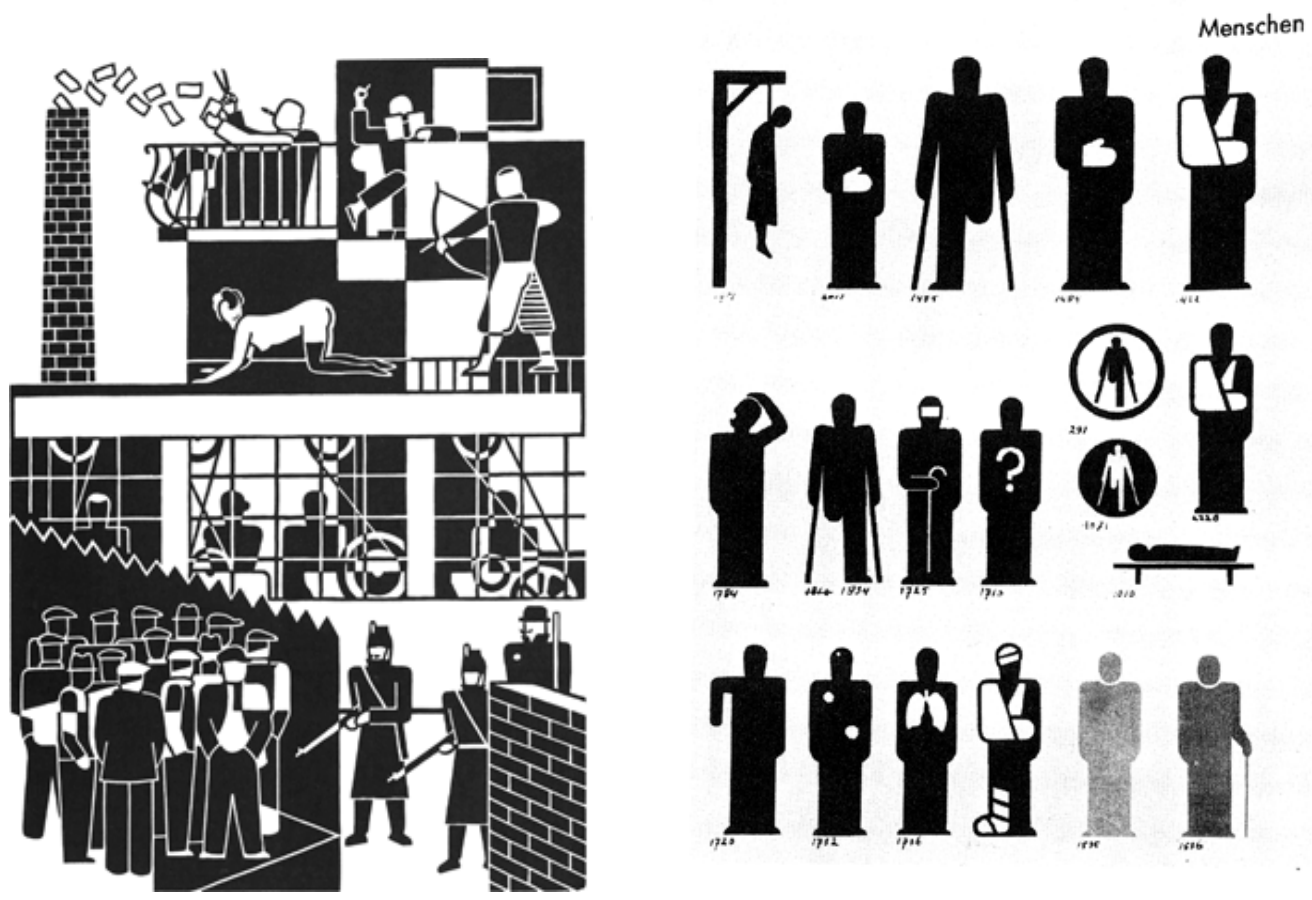

Figura 1 - (à esquerda) Gravura de Gerd Arntz de 1926, (à direita) exemplo do trabalho posterior de Arntz para IS OTYPE. (Fontes: <www.gerdarntz.org>, TWYMAN, 1975)

Entre o fim dos anos de 1920 e o começo de 1930 a equipe de Neurath era formada por 25 pessoas, divididas em três grupos: os coletores de dados, os "transformadores" e os artistas gráficos, como eram chamados. A fase inicial do processo era feita pelos coletores de dados que eram economistas, historiadores e especialistas em estatística. Em seguida os "transformadores" organizam e editavam a informação coletada, Twyman (1975) descreve estes últimos como editores visuais, que eles precisavam conhecer o dados coletados e ter a capacidade de projetar a configuração final dos elementos, embora não tivessem necessariamente o conhecimento para finalizar o processo. O estágio final ficava ao encargo dos artistas gráficos, que desenhavam os símbolos e as artes-finais.

Nos anos de 1920, os dois transformadores eram Marie Neurath (esposa de Otto Neurath) e Friedrich Bauermeister. Marie Neurath, embora formada em física e matemática, também se dedicara ao estudo arte,e foi uma das figuras mais importantes no planejamento e no processo de "transformação" do ISOTYPE, além de acompanhar Neurath em seus vários projetos durante a sua vida (TWYMAN,1980).

Em 1931 Neurath é convidado a criar um Museu de Economia e Sociedade em Moscou, e seu método de estatística unindo linguagem visual é adotado oficialmente pelo estado soviético. A essa altura as exposições são criadas com elementos gráficos padronizados e reproduzíveis.

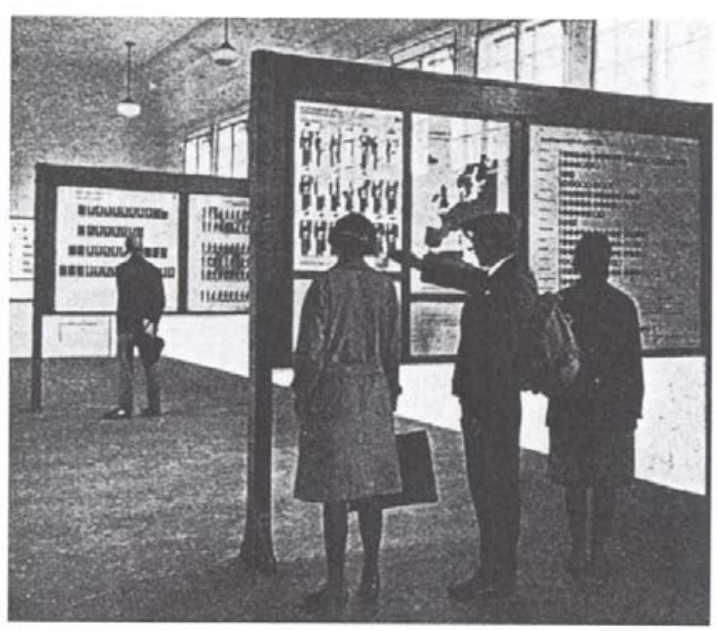

Figura 2 - Exemplo do uso de gráficos de estatística no Museu de Economia e Sociedade de Viena no início dos anos de 1930. As exposições eram compostas por telas dobráveis de $125 \times 126 \mathrm{~cm}$. (Fonte: Gesammelte bildpadagogische Schriften, 1991). 
Porém, a pa rtir de 193 4, com a repressão e pe rseguição ao s sociali stas pel o nazi -facismo, Neurath é forçado a exilar-se na cid ade da Ha ia, na Hola nda. Lá, ele continua se u trabalho, criando a Fundação Internacional para a Educação Visual e dando inicio à su a Enciclopédia das Ciências Unificadas. Entre 1936 e 1 938, publica o International Picture Language, de screvendo detalhadamente o s istema ISOTYPE, e o s eu livro De moderne mensch onstaat (A criação do Homem Moderno).
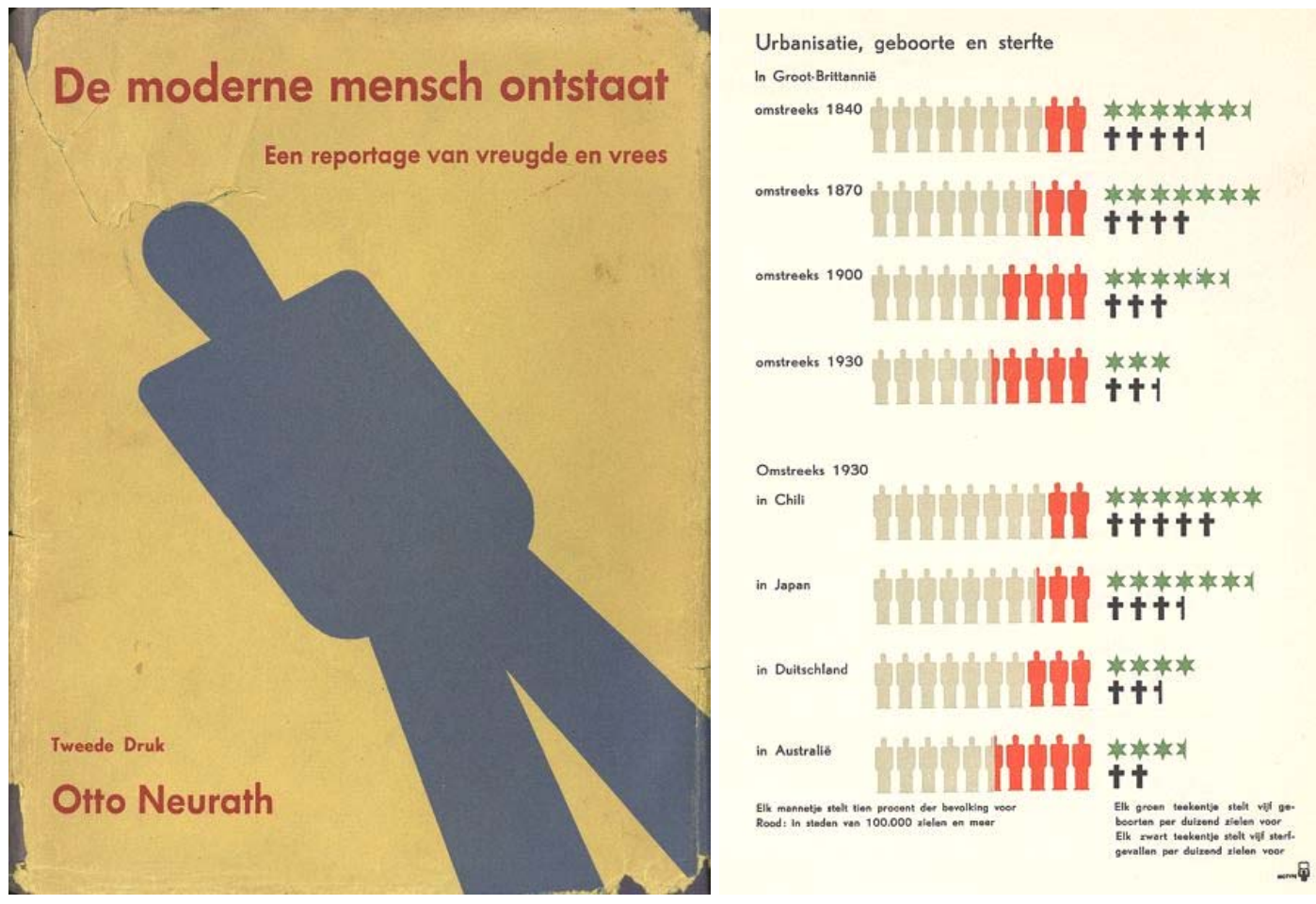

Figura 3 - Cap a e diagrama (p.58) do livro A criação do Homem Moderno. O diagrama da direita descreve taxas de nascimento e mortalidade de diferentes países em determinadas épocas. (Fonte: De moderne mensch onstaat, 1938.)

Em 1940, com a expansão do nazi-facismo pela Europa, Neurath foge em direção ao porto de Scheveningen, mas é interceptado por um navio destroyer britânico. Esse desvio fortuito o leva à Inglaterra, onde ele começa a ensinar em Oxford, e onde funda o Instituto ISOTYPE, produzindo exposições, documentários filmados e vários livros. Em 1945, Otto Neurath morre subitamente, mas Marie Neurath continua o projeto ISOTYPE (CARTWRIGHT, 1996).

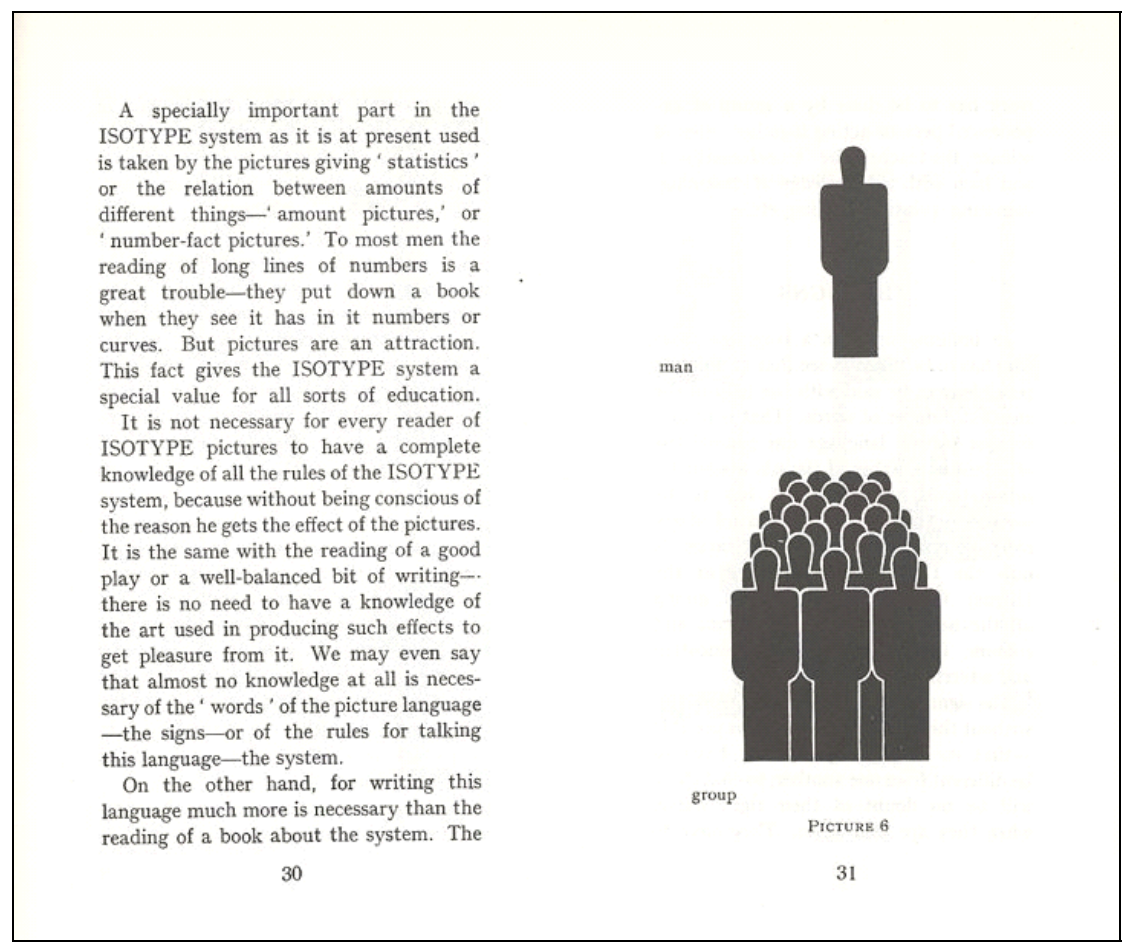

Figura 4 - Duas páginas de uma edição, em Inglês, da International picture language /Internationale Bildersprache. (Fonte: NEURATH, 1936). 


\section{O Sistema ISOTYPE}

No International picture language /Internationale Bildersprache, publicado em 1936 em Londres, Neurath descreve detalhadamente o sistema ISOTYPE, deixando claro que esse sistema foi criado como auxílio à educação.

O sistema ISOTYPE era composto por uma determinada configuração de símbolos pictográficos que Neurath chamava de "signos", que poderiam ser modificados dependendo do contexto da informação a ser descrita. Esses pictogramas eram organizados seguindo uma sintaxe precisa desenvolvida por Neurath e sua equipe. O sistema ISOTYPE deveria, primeiramente, oferecer os fatos mais importantes da proposição que estivesse descrevendo e, para tanto, o designer deveria seguir as regras propostas no sistema.

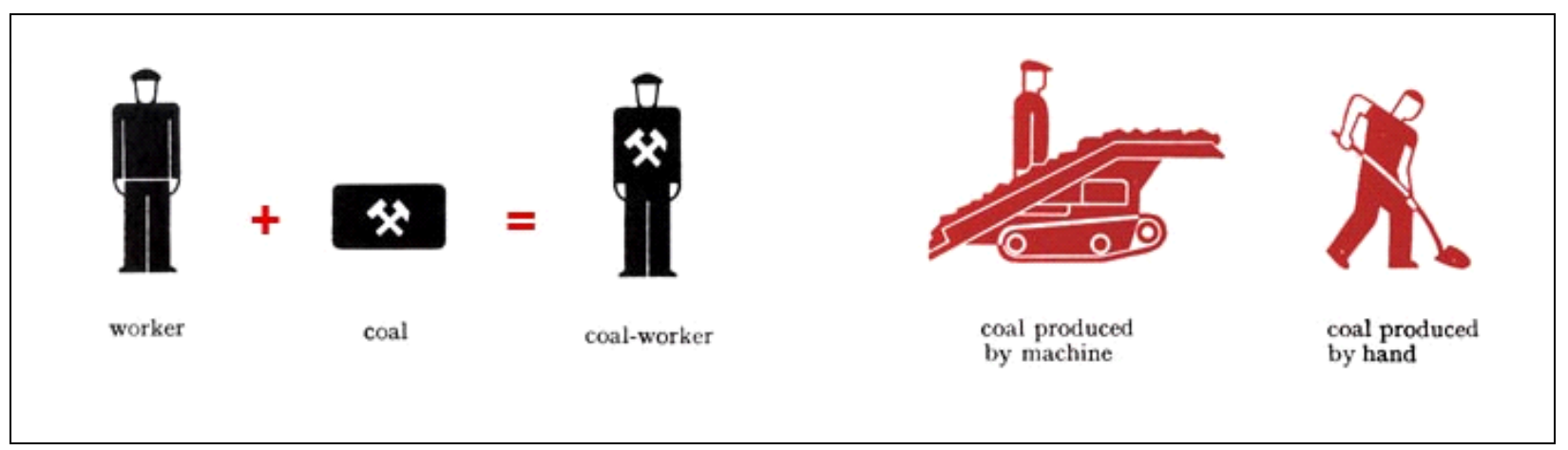

Figura 5 - Diag rama adapt ado do International picture language /Internationale Bildersprache (1936). Esse diagrama descreve as regras para a criação de pictogramas do ISOTYPE. (Fonte: TWYMAN, 1975)

Os símbolos do ISOTYPE eram projetados para serem auto-explicativos. Os desenhos extremamente sintéticos de Gerd Artz, sem descrever as faces do rosto ou muitos detalhes da roupa, davam aos símbolos uma sensação de generalidade. O símbolo para "trabalhador" não representava um trabalhador específico, mas trabalhadores em geral. Caso fosse necessário especificar que o trabalhador é um mineiro, um símbolo adicional para carvão era criado e adicionado ao pictograma principal de trabalhador. Caso o pictograma descrevesse um contexto mais amplo como "carvão produzido por uma máquina" ou "carvão produzido manualmente" pictogramas específicos eram criados.
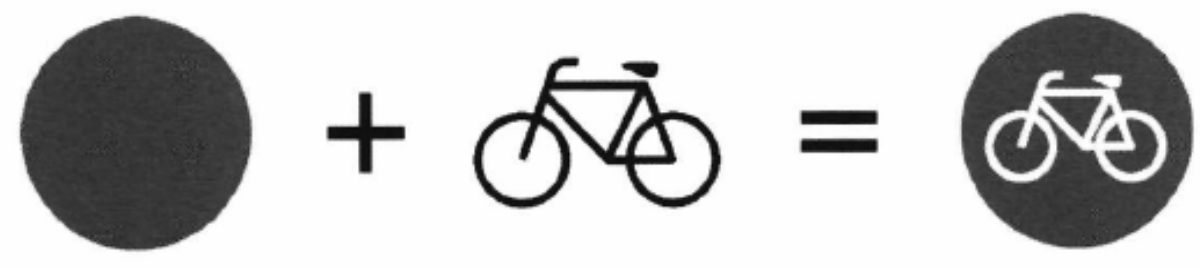

Figura 6 - Exemplo dos pictogramas para o Departamento de Transporte norte-americano Fonte: Engelhardt (2002:47)

Na figura 6, Yuri Engelhardt (2002:47) mostra como os pictogramas de trânsito contemporâneos são compostos em uma relação em que símbolos contêm outros símbolos. Observando as regras de criação de símbolos do ISOTYPE (figura 5) percebemos uma clara semelhança. Como veremos adiante, os símbolos do ISOTYPE viriam, de fato, a influenciar a criação de pictogramas internacionais.

Além da forma de cada símbolo, o sistema do ISOTYPE propunha uma maneira diferente de organização dos elementos da comunicação. Essa sintaxe procurava privilegiar uma compreensão mais imediata. Para Neurath, gráficos que privilegiavam o tamanho ou formas abstratas, como era o costume na época, dificultavam a compreensão.

Em seu International picture language, Neurath (1936) propõe várias convenções, entre elas:

1. Um signo ou símbolo deve ser usado para representar certa quantidade de coisas, e um numero maior de símbolos para um numero maior de coisas. (um problema surge aqui quando 


\section{Infadesıgn}

frações precisam ser representadas.)

2. Os símbolos devem ser do mesmo tamanho e devem ser espacejados igualmente; alguns símbolos básicos podem ser combinados.

3. Em circunstâncias normais a escala de tempo de um gráfico deve ser demonstrada em um eixo vertical, e as quantidades e somas na horizontal. Gráficos devem ser li dos de cima para baixo, e da esqu erda para a direita, pre servando o movimento natural dos ol hos na leitu ra de prosa.

4. Perspectiva não d eve se r utiliza da. Q uando co isas pre cisam ser re presentadas em trê s dimensões então modelos ou desenhos isométricos devem ser usados.

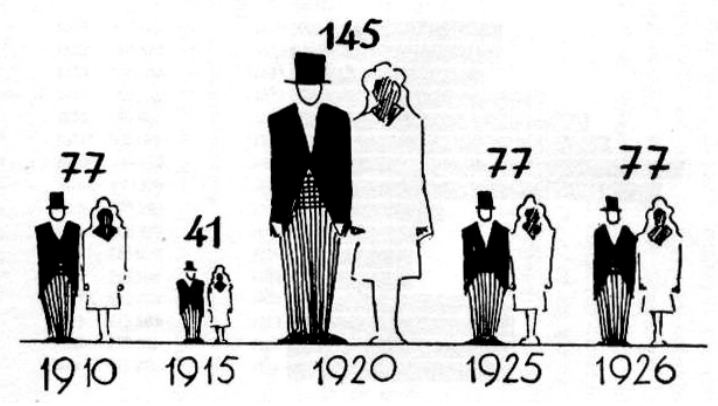

Figura 7 - Exemplo, oferecido por Neur ath, de um sistema problemático, onde a relação de quantidade, em um gráfico, é determinada pelo tamanho dos elementos gráficos. (Fonte: NEURATH, 1936).

Para ele, um gráfico era mais preciso e claro quando valorizados o agrupamento de elementos, as diferenças entre elementos e suas quantidades. Representar um homem grande e outro pequeno acompanhado por números era, segundo Neurath, uma solução pobre e visualmente imprecisa (Figura 7). No entanto, vários pictogramas representando quantidades determinadas ofereciam, sem muita explicação ou ambigüidade, a informação necessária, como podemos ver no gráfico de nascimentos e mortes na Alemanha entre 1911 e 1926 (Figura 13). Esses eram os casos mais típicos do ISOTYPE, e essas regras podiam ser adaptadas, por exemplo, para gráficos com mapas ou até diagramas seqüenciais descrevendo uma ação.

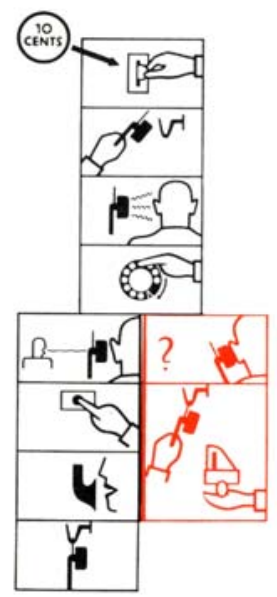

Number of Men Living in Europe
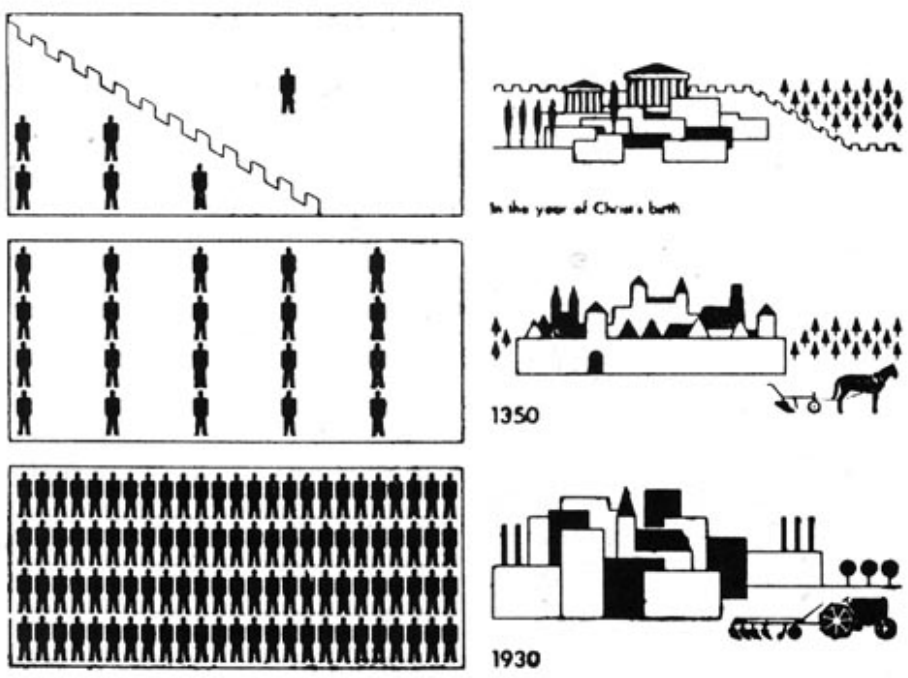

I sign for $5,000,000$ men

Figura 8 - Dia gramas seqüen ciais do International picture language /Internationale Bildersprache. O primeiro (p.19) descreve o uso do telefone e o segundo (p.25) descreve o número de pessoas vivendo na Europa desde a Antiguidade até 1930. (Fonte: NEURATH, 1936) 


\section{O legado do ISOTYPE}

O ISOTYPE teve grande influência sobre o design de informação desde os anos de 1930. Podemos perceber sua influencia nos pictogramas, diagramas e infografia, além do importante papel do "transformador" de informação.

Quando Neurath e Arntz criaram a representação pictográfica de um homem para o ISOTYPE, sem enfatizar detalhes convencionalmente naturalistas da figura, estavam sugerindo uma idéia de generalidade da raça humana. Para Ellen Lupton (1989), "um pictograma do ISOTYPE é semelhante a uma formula científica (...) essa figura, para Neurath, era uma expressão de neutralidade" (1989:50).

Essa "neutralidade" era conseguida através da simplificação formal. Isso possibilitava que cada figura pudesse ser repetida em um gráfico, substituindo representações abstratas quantitativas, como números ou formas geométricas. Neurath acreditava na universalidade da linguagem visual. Para ele, basear-se apenas na linguagem gráfica verbal poderia criar fronteiras culturais de compreensão junto ao público. Isso não significa que Neurath e Arntz tenham conseguido criar figuras verdadeiramente "neutras". Contudo, seus pictogramas eram construções que atendiam, de forma eficiente, ao tipo de representação necessária aos infográficos quantitativos do ISOTYPE.
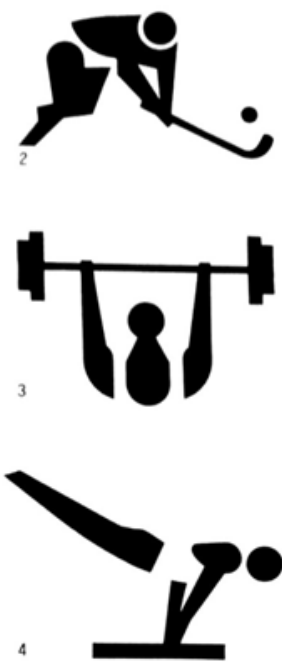
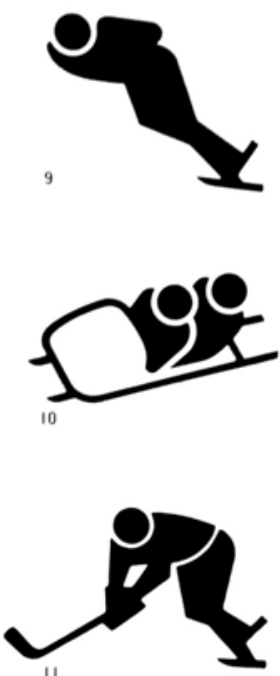
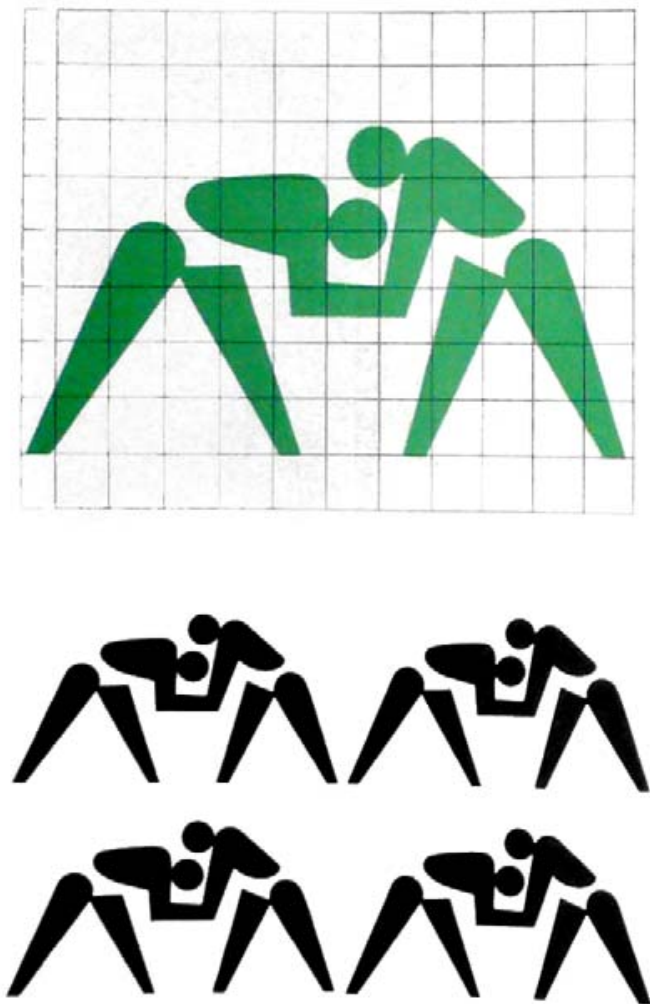

Figura 9 - Pictogramas para as olimpíadas de Tóquio por Masaru Katzumie (1964). (Fonte: OTA, 1985) 

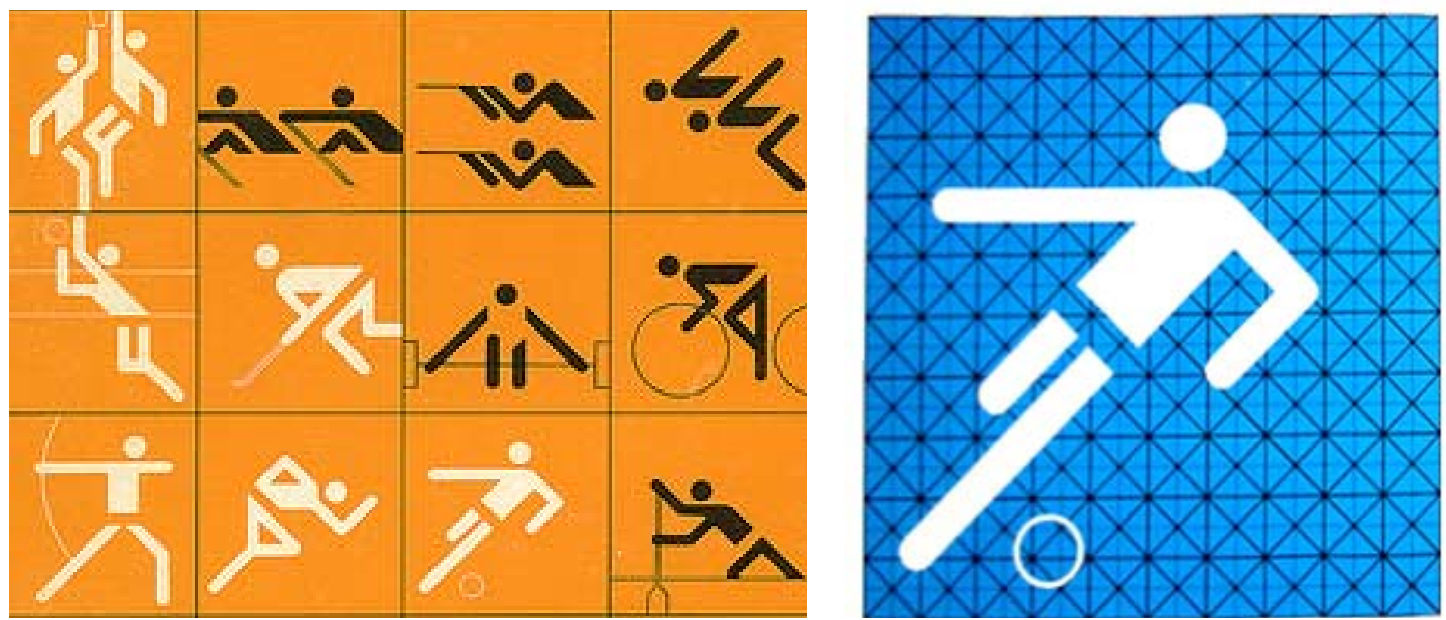

Figura 10 - Pictogramas para as olimpíadas de Munique por Otl Aicher (1972). (Fonte: HERDEG, 1978)

No caso específico dos pictogramas, especialmente a partir dos anos de 1960, houve um interesse semelhante ao projeto inicial do ISOTYPE no momento em que designers começam a tentar criar um padrão internacional de pictogramas para sinalização. Em 1964, Masaru Katzumie cria um sistema de pictogramas para as Olimpíadas de Tóquio, claramente inspirado no ISOTYPE, e, em 1972, Otl Aicher desenvolve um sistema semelhante ao de Katzumie para as Olimpíadas de Munique.
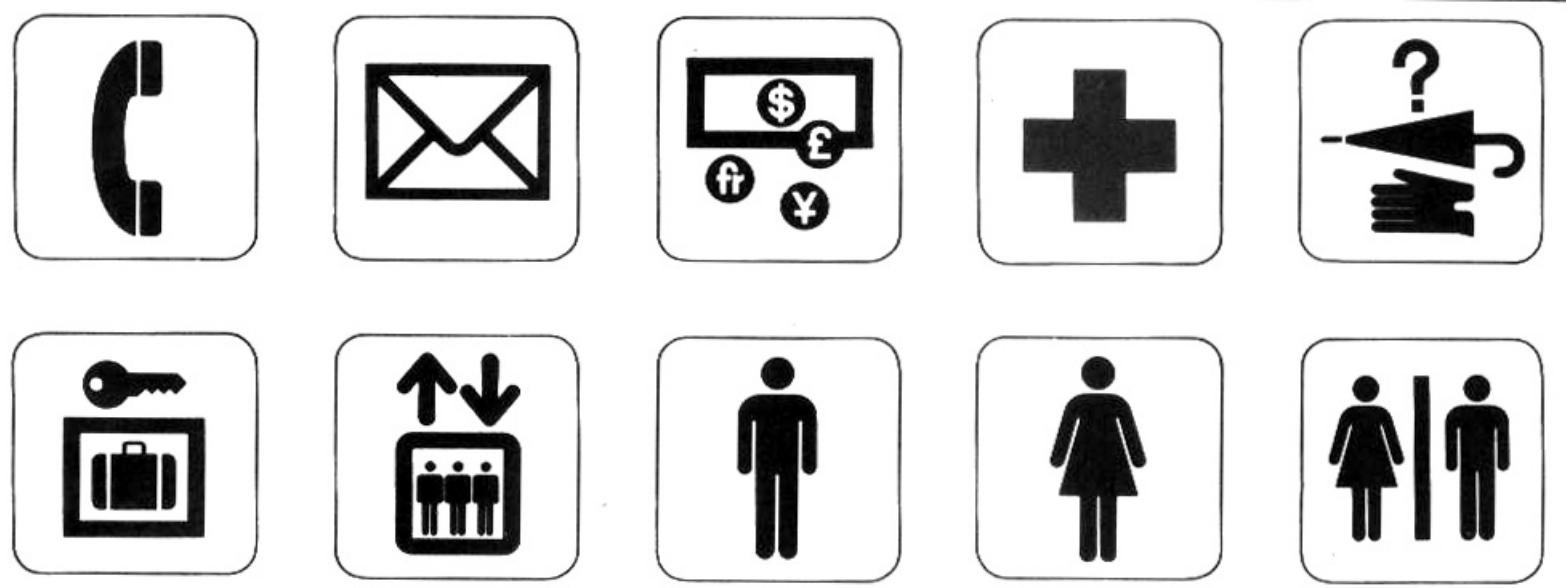

Figura 11 - Exemplo dos pictogramas para o Departamento de Transporte norte-americano (Fonte: AIGA, 1976)

Mas foi em 1976, quando o AIGA (American Institute of Graphic Arts) criou para o departamento de transporte norte-americano um sistema de sinalização pictográfico, que surgiu o primeiro padrão internacional no uso de pictogramas. Segundo Herdeg,

"linguisticamente nosso mundo é uma Babel, e na falta de uma linguagem universal a única forma rápida de transmitir informação está nos signos - e o designer gráfico deve vir ao nosso auxílio quando o mundo nos falha" (HERDEG,1978:40). Nesta afirmação, enaltecendo o processo de estandardização internacional de pictogramas de sinalização, percebemos a intenção clara de se criar um tipo de linguagem internacional pictórica.

Neurath faz uma afirmação semelhante:

O método ISOTYPE talvez se torne um dos fatores que irão ajudar a criar uma civilização onde todas as pessoas compartilham uma cultura comum e o vão entre as pessoas educadas e as não educadas poderá desaparecer (NEURATH, 1940).

Embora o projeto de pictogramas da AIGA seja apenas voltado para sinalização, ele talvez seja uma das propostas que mais se assemelham ao plano original do ISOTYPE, ou seja: uma linguagem que ultrapassa antigas barreiras culturais. 
É provável que a cultura do ISOTYPE tenha chegado ao Brasil através desta estandardização internacional dos pictogramas. Com a difusão do uso de pictogramas em ambientes públicos, muitos designers brasileiros se interessaram pela possibilidade de dar mais personalidade aos pictogramas de seus projetos. Um exemplo disso é o sistema de pictogramas para o RioZoo, Zoológico do Rio, realizados por Evelyn Grumach em 1976 para o escritório de Aloísio Magalhães, PVDI. Nesse sistema, podemos perceber uma quebra com as determinações gerais dos pictogramas da AIGA: os desenhos são mais livres, aparentemente sem uma estrutura geométrica pré-definida, dando personalidade para as figuras representadas. Eles utilizam o espaço negativo branco no interior dos desenhos, dando a aparência de contornos. O desenho em negativo destes pictogramas possibilitou mais detalhe e personalidade para o desenho, oferecendo um contraponto ao estilo "neutro" dos pictogramas dos AIGA.
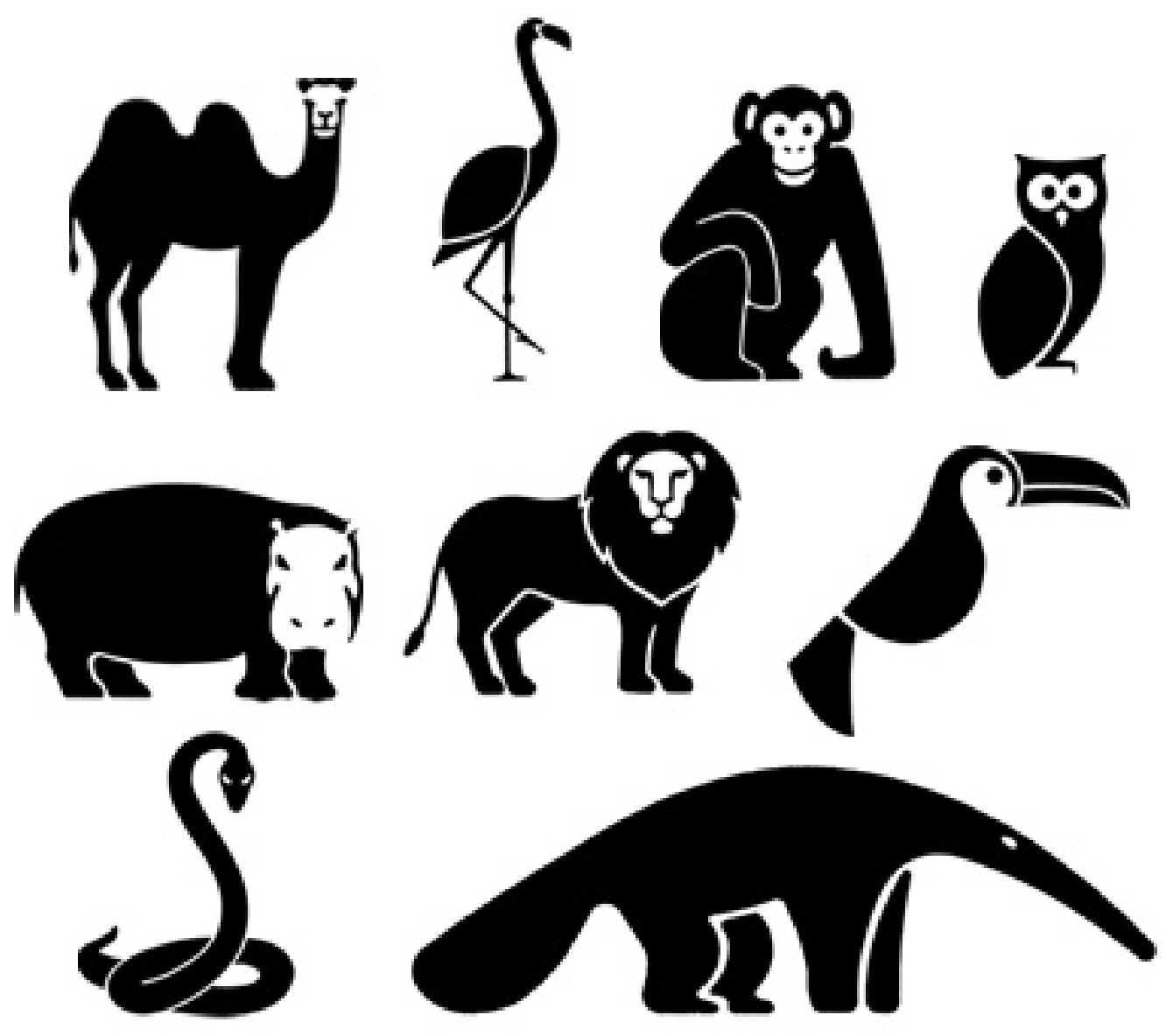

Figura 12 - Sistema de pictogramas para a sinalização o RioZoo realizados por Evely n Grumach, em 1976, para o escritório de Aloísio Magalhães, PVDI. (Fonte: Portfolio Brasil: eg.design, 2005)

\section{Diagramas e infografia}

Em se tratando de diagramas e infografia, a influência do ISOTYPE é muito diversificada e difícil de determinar. No entanto, Robin Kinross (2000) sugere que a organização visual proposta pela equipe de Neurath em seus infográficos talvez seja o grande legado do ISOTYPE e que as tentativas de imitação costumam ser mal sucedidas:

Os pictogramas são apenas parte da história. A minha visão da versão completa dessa história envolve a organização ou configuração de elementos, palavras ou imagens. (...) O melhor do ISOTYPE, que é o que Michael Twyman viu ao descobrir e adquirir o arquivo para a Universidade de Reading seria a lógica dessa organização. O que não é apenas colocar elementos em ordem da esquerda para a direita. Por exemplo, no caso do famoso gráfico de mortes e nascimentos, os nascimentos estão ordenados para uma direção e a morte para outra. É uma solução simples, mas que começa se tornar complexa. Ele tem um sistema que você talvez possa colocar em palavras e descrever o funcionamento para outra pessoa. No entanto, nas imitações do ISOTYPE, você vê como outras pessoas não compreendem o sistema. As imitações parecem grosseiras (KINROSS, 2000:1) 


\section{Infodesıgn}

Births and Deaths in Germany in a Year

$1911 \cdot 14$

$1915 \cdot 18$
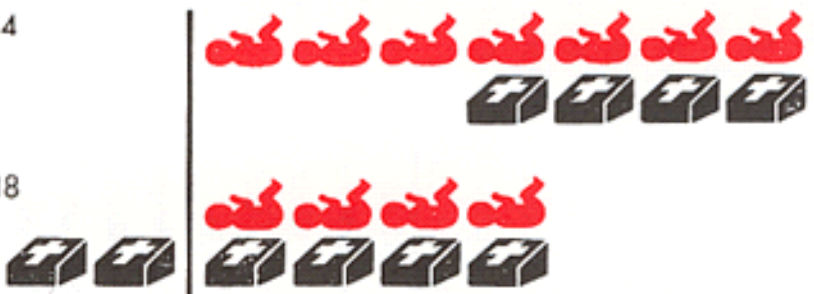

$1919 \cdot 22$

$1923 \cdot 26$
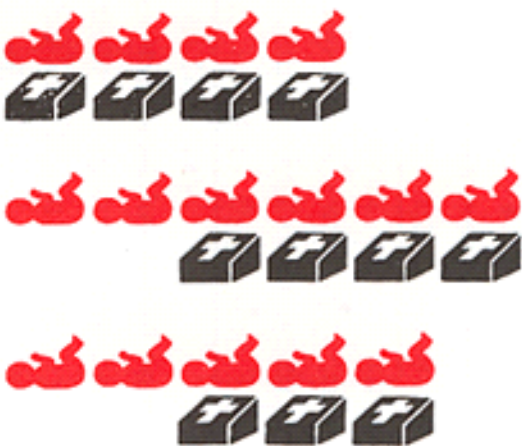

1 red sign for 250,000 births a year

I black sign for 250,000 deaths a year

Figura 13 - Nascimentos e mortes na Alemanha entre 1911 e 1926 é um famos o diagrama do I SOTYPE da déc ada de 1920. Na forma clara em o diagrama foi montado, percebemos rapidamente os efeitos sobre a taxa mortalidade durante a primeira guerra mundial.

Podemos concluir então, pelas afirmações e exemplos dados por Kinross, que a estruturação e o uso de elementos pictográficos visuais nos infográficos do ISOTYPE podem ter modificado a forma de

muitos designers trabalharem, sem que precisassem necessariamente copiar diretamente o sistema de Neurath.
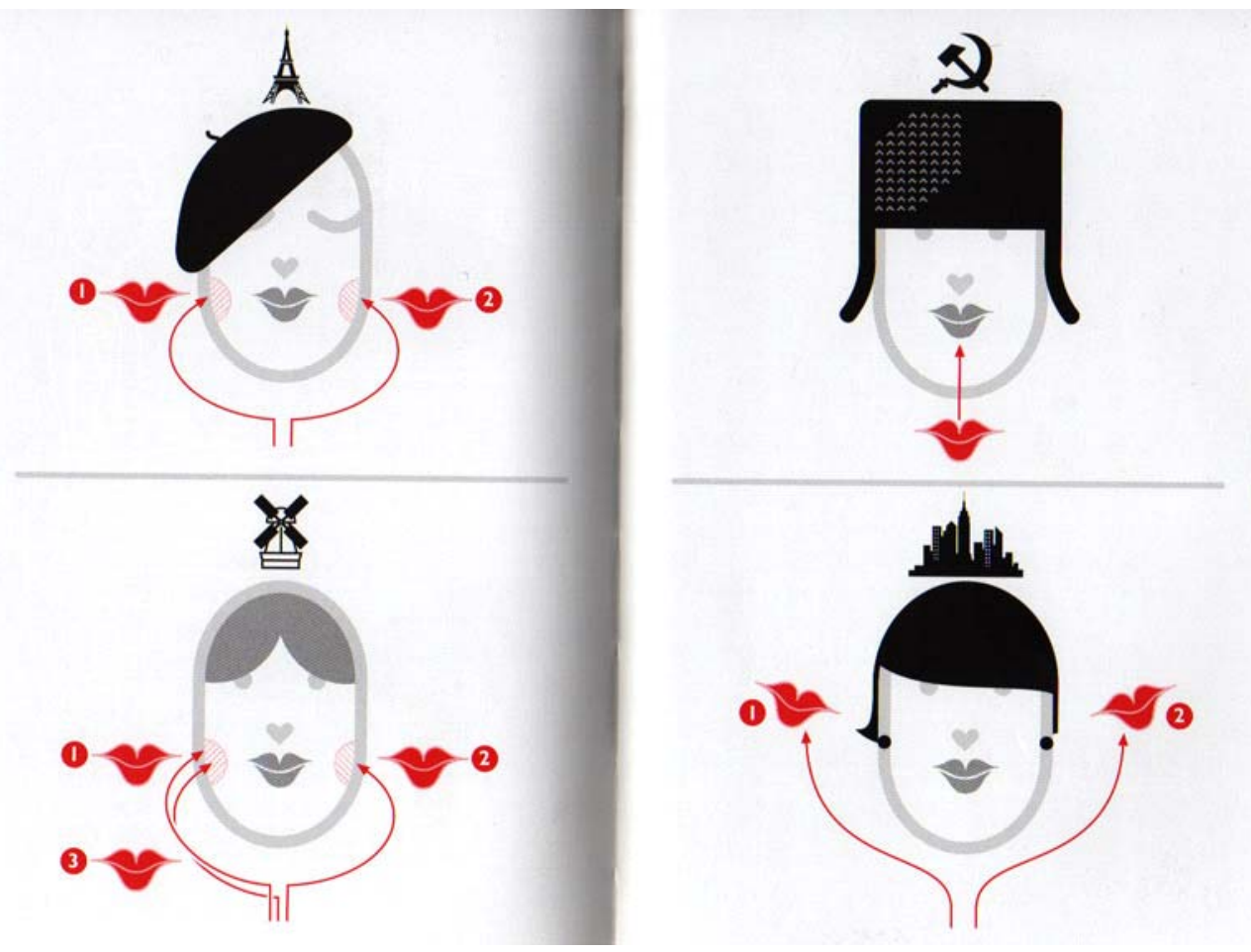

Figura 14 - - Esse diagrama, se m palavras, de Nigel Holmes, descreve diferentes formas de se beijar em quad ro países. (Finte: Wordless Diagramas, 2005, p.146-147)

Um dos casos mais interess antes, de um a clara influênc ia do s istema do ISOTYPE, é o trabalho do infografista Ni gel Holme s. No exemplo da figura 13 de Holm es (2005), pode mos observar um a se qüência de dia gramas de screvendo difere ntes formas de se beijar em quadro 
países. No s exemplos de Wordless Diagrams, Holmes segue o pri ncípio d e Neurath d e qu e imagens conseguem expressar um argumento claramente sem necessariamente usarem palavras. No entanto esse estilo, ao contrário do trabalho do ISOTYPE, consegue ex pressar um senso de humor sutil, unind o um estilo obj etivo, qua se pictográfico e atento ao espaço neg ativo g ráfico como o de Arntz, com a simplicidade de um desenho de cartum.

\section{MALOOUEIRO E SOFREDOR}

\begin{abstract}
Era para ser no ano passado, mas ficou para 2008. Segundo o relatório da ONU Estado da Populaçăo Mundial, pela primeira vez na história mais da metade da populaçăo do planeta viverá em cidades. Bom ou ruim? As duas coisas. Bom porque as cidades oferecem melhor acesso a saúde, educaçăo, informaçăo e conhecimento. Ruim porque 1 bilhăo

dos habitantes urbanos săo pobres ou miseráveis, vivendo à margem desses beneficios. o QUE FAZER Investimento pesado em infra-estrutura básica nas favelas. Um setorchave é o planejamento familiar. Mulheres que vivem em favelas têm menor acesso a contraceptivose taxas de fertilidade mais altas que as moradoras de áreas ricas.
\end{abstract}

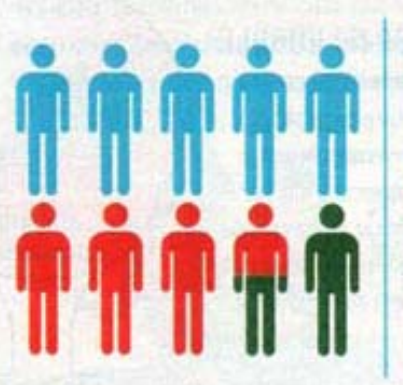

DECADA 10SERES HUMANOS... 5 VIVEMNOCAMPO 3,5 UIUEM NACIDADE (AAREASNADOPOBRES) 1,5 UIVE EMFAUELRS

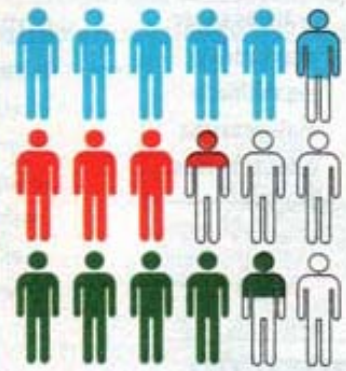

MÉDIA DE FILHOS POR MULHER*

5,G ZONARURRL

3,2ZONAURBANA [MREASAPDOBRE]

4,3 FAVELAS

'Média das taxas de fertilidade em?

paises africanos. Fonte: 0 NU.

Figura 15 - Infográfico de Bruno Oliveira. Esse infográfico possui uma configuração visual muito semelhante a do ISOTYPE. (Fonte: Revista Superinteressante de Janeiro de 2008, p. 70, n. 248).

No caso da infografia brasileira, também podemos perceber a influencia do ISOTYPE até os dias de hoje. Uma prova clara disso é um infográfico retirado da Revista Superinteressante, de janeiro de 2008, (figura 14). Com uma configuração visual muito semelhante ao sistema do ISOTYPE, este infográfico usa pictogramas para representar quantidades específicas que ilustram estatísticas de uma matéria relacionando à vida no campo, nas cidades e nas favelas. 


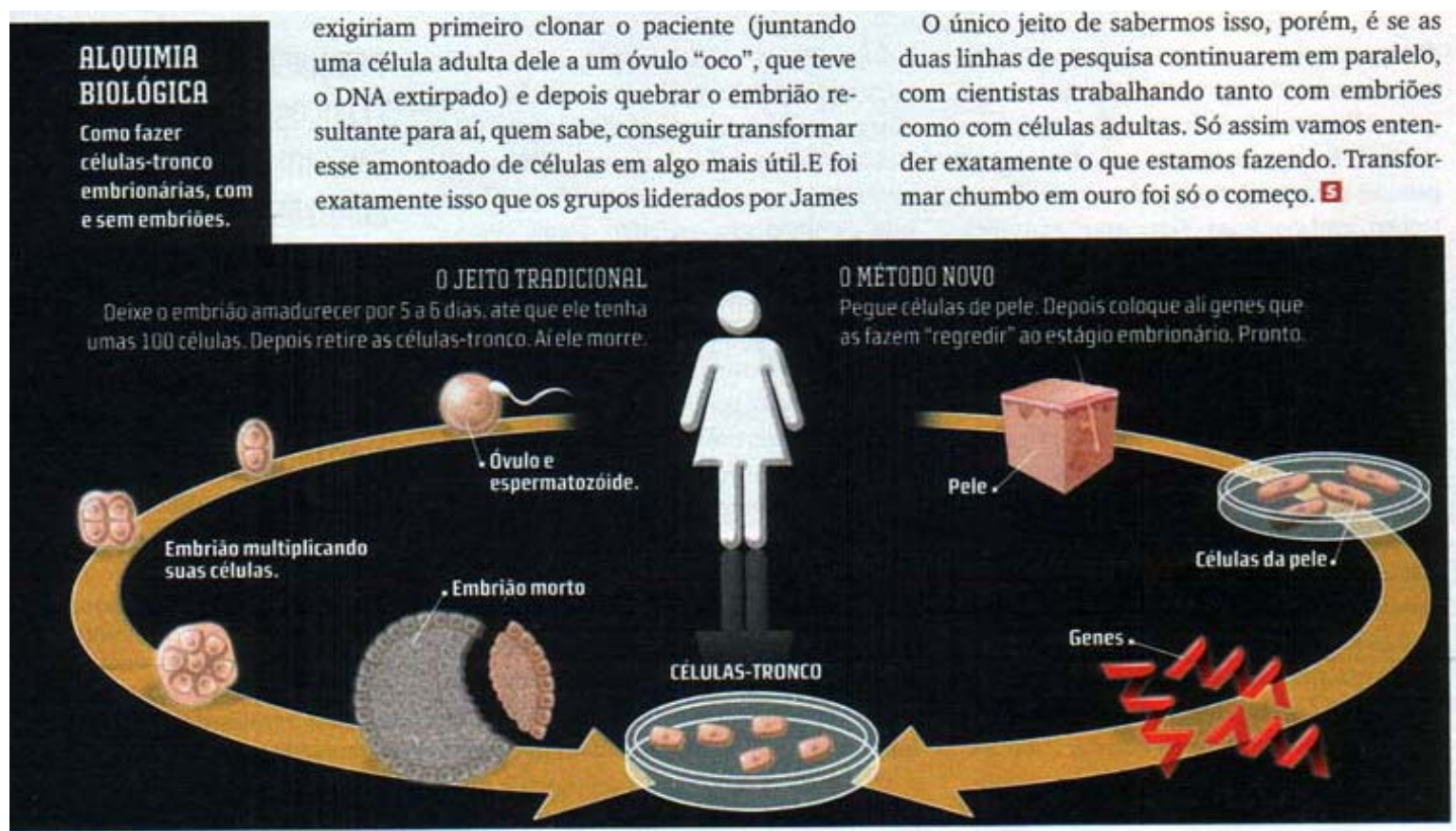

Figura 16- Infográfico de Luís Iria, demonstrando duas seqüências distintas de criação das células-tronco. ( Fonte: Revista Superinteressante de Janeiro de 2008, p. 28, n. 248).

Na mesma edição desta revista podemos encontrar outro infográfico (figura 15) que usa a linguagem pictográfica. Neste exemplo o pictograma é usado para simbolizar o gênero feminino humano como um todo, que origina duas seqüências de elementos gráficos naturalistas, acompanhados por setas. Esse contraste de tratamento gráfico sugere uma hierarquia entre elementos gráficos, diferenciando o elemento principal dos dois processos biológicos, mais detalhados. Esse é mais um exemplo da simplificação da forma humana em uma linguagem pictográfica que remonta às soluções formais do ISOTYPE.

\section{O "transformador" da informação}

Um dos legados menos comentados do ISOTYPE não está diretamente ligado às estratégias formais de design, mas na própria relação entre a equipe de design e o "conteúdo" informacional. Atualmente, esse tem sido o foco do design da informação. Sue Walker (2007) afirma que o design da informação é uma atividade que têm se desenvolvido bastante, nos últimos anos, como uma área voltada para a o design gráfico, mas que se relaciona com a lingüística aplicada, a psicologia aplicada, e a ciência da informação, entre outras áreas. O design da informação está voltado aos sistemas de informação com o objetivo de otimizar o processo de aquisição de informação (SBDI, 2008).

Podemos considerar que esse processo de otimização, dos designers de informação, também pode ser considerado uma forma de "transformação"'da informação. O conceito do "transformador", proposto nos anos de 1930 por Neurath, é o de um tipo de profissional que reinterpreta a informação, ou transforma a mesma, para se adequar a contextos sociais diferentes. Para Neurath designers eram intermediários entre historiadores, economistas e matemáticos, e seu público alvo (WILBUR,1998:7).

Segundo Waller e Macdonald-Ross, no processo de design da informação a figura central deve ser um "comunicador profissional habilidoso para mediar entre o especialista e o leitor" (2000:178). Para eles, esse profissional, ou equipe, já havia sido concebido por Neurath muito antes do conceito de design da informação. Embora o conceito do "ransformador" tenha "retornado" recentemente, ele pode ter um papel importante no desenvolvimento do design voltado para a educação e para o mercado editorial.

Contudo, esses são apenas alguns dos exemplos mais evidentes do legado do ISOTYPE. Fica difícil determinar a totalidade da influência da visão de Neurath, de sua equipe, e dos modelos de representação gráfica de Arntz. Pode-se indagar, por exemplo, até que ponto o próprio estilo do desenho de Arntz não teria influenciado a representação científica de neutralidade contemporânea. Essa é uma reflexão mais ampla do que a proposta neste artigo, pois existem muitos outros fatores culturais, difundidos pelo design moderno, a serem considerados. Todavia, não há dúvida de que estamos apenas começando a mapear o legado do ISOTYPE. 


\section{ISOTYPE e o pós-modernismo: considerações finais}

Neurath foi um modernista e seus projetos parecem estar sempre sugerindo soluções totalizantes, tipicamente modernas. Michael Twyman (1976), Okio Ota (1987) e muitos outros, que se dedicaram a compreender o projeto de Neurath, criticam o fato do uso do sistema ISOTYPE não ter continuado fielmente até os dias de hoje. Será que isso não ocorreu por falta de empenho, ou interesse, de designers em geral? Ou apenas porque as pessoas não desejam padrões internacionais de linguagem? Uma das lições do pós-modernismo é que os projetos unificados modernos, por mais influentes que sejam, não vingaram completamente. Isso de deveria ao fato de que tais projetosofereciam pouca variedade, sem necessariamente oferecer soluções mais específicas para atender às necessidades dos usuários em seus contextos culturais.

Um exemplo disso seria o Aeroporto Charles De Gaulle, em Roissy, Paris, para o qual o tipógrafo Suíço Adrian Frutiger criou uma sinalização puramente tipográfica, incluindo apenas setas como símbolos (HERDEG, 1978:78-79). Essa escolha reflete o fato de que a linguagem pictórica não é necessariamente universal. Em um aeroporto internacional, nem sempre pessoas de diferentes países compreenderiam um pictograma da mesma maneira. O exemplo de Frutiger é um entre vários que mostram que, seja por problemas de contexto cultural, ou por simples desejo de variedade, os grandes projetos modernos precisam ser relativizados para sobreviverem.

No entanto, seria interessante considerarmos se o próprio Neurath teria compreendido a forma diversa em que o ISOTYPE influenciou outras gerações. Embora Neurath seja acusado de ter uma visão aparentemente restrita da comunicação e da ciência, ele revelou-se, muitas vezes, flexível em suas propostas, aceitando modificações nos diagramas para países de culturas muito diferentes (TWYMAN, 1976).

Em uma famosa citação, Neurath descreve cientistas como marinheiros que estão constantemente reconstruindo o próprio barco no alto mar:

Onde um pedaço do casco é retirado um novo deve substituí-lo imediatamente e para tanto o resto no navio deve servir de suporte. Os marinheiros usam pedaços de madeira da velha estrutura para modificar o esqueleto e casco do navio. Mas eles não podem levar o navio a terra e começar do início. Durante esse trabalho, eles se mantêm na velha estrutura e suportam as fortes ventanias e ondas da tempestade. Esse é o nosso destino. (NEURATH apud QUINE, 1960:3)

Embora Neurath pareça acreditar na existência de uma paleta de elementos fixos, compondo o conhecimento, nesta citação ele amplia essa visão. Nessa alegoria, o barco é o próprio conhecimento que está sendo constantemente reconstruído,ou seja: para Neurath, o processo de criação de conhecimento científico não é fixo, mas um fluxo constante. Essas duas afirmações, aparentemente paradoxais, mostram que as idéias de Neurath não eram absolutas, como talvez se imagine. O conhecimento de uma geração pode servir como ferramenta para o desenvolvimento de idéias das gerações futuras. Refletindo sobre o papel do ISOTYPE, podemos perceber que as idéias de design de Neurath e sua equipe, tem sido uma fonte rica de inspiração e conhecimento para as gerações seguintes.

\section{Referências}

CARTWRIGHT, Nancy et al. Otto Neurath: Philosophy Between Science and Politics. Cambridgemew York: Cambridge University Press,, 1996.

ENGELHARDT, Yuri. The language of graphics. Amsterdam: Sewn, 2002. Disponível em: <http://dare.uva.nl/document/66041> Acesso em 28 ago. 2008.

HERDEG, Walter. Archigraphia. Zurich: Graphis, 1981.

HOLMES, Nigel. Pictograms: A view from the drawing board or, what I have learned from Otto Neurath and Gerd Arntz (and jazz). Information Design Journal, Volume 10, no.2, pp. 133144(12). 2001.

Nigel. Wordless Diagrams. New York: Bloomsbury, 2005.

KINROSS, Robin; OVEN, Petra Cerne. An interview with Robin Kinross (2000.08.21). Disponível em: <http://www.hyphenpress.co.uk/journal/2000/08/21/kinross_interview>. Acesso em 14 jan. 2007.

LUPTON, Ellen. Reading Isotype. MARGOLIN, Victor (ed.) Design Discourse: History, Theory, Criticism. Chicago: University of Chicago Press, 1989. 


\section{Infadesıgn}

MODLEY, Rudolf. Handbook of pictorial symbols. New York: Dover, 1976.

NEURATH, O. International Picture Language. Reading: The University of Reading Press, 1980.

NEURATH, O. De Moderne mensch onstaat Amsterdam: Noord-Hollandsche Uitgevers Maatschappij, 1940.

OTA, Yukio. Pictogram Design. Tokio: Kashiwa Shobo Publishers, 1987.

QUINE, Willard. Word and Object. Cambridge: MIT Press. 1960.

The American Institute of Graphic Arts. Symbol Signs. Washington: Dpt. of Transportation, 1974.

Sociedade Brasileira de Design da Informação, bem-vindos ao site da sbdi. Disponível em http://www.sbdi.org.br. Acesso em 23/09/2008.

TWYMAN, Michael. The significance of Isotype. In: M. Twyman. Graphic communication through ISOTYPE. Reading: University of Reading, p. 7-17. 1975.

,. Using pictorial language: a discussion of the dimensions of the problem. In T. M. Dufty and R. Waller (eds.) Designing usable texts. Orlando: Academic Press, p. 245-312. 1985.

WALKER, Sue, BARRAT, Mark. An introduction to information design. 2007. Disponível em: $<$ http://www.designcouncil.org.uk/en/About Design/Design Disciplines/Information Design b y Sue Walker and Mark Barratt//> Acesso em 21 set. 2008.

WALLER, Robert; MCDONALD-ROSS, Michael. The Transformer Revisited. Information Design Journal, vol. 9, pp.177-194. 2000.

WILBUR, Peter, BURKE, Michael. Information Graphics: Innovative Solutions in Contemporary Design. London: Thames \& Hudson, 1998.

\section{Sobre o autor}

Ricardo Cunha Lima é mestrando da ESDI/UERJ, possui graduação em Comunicação Visual pela Pontifícia Universidade Católica do Rio de Janeiro. Atualmente é professor substituto da Universidade Federal do Rio de Janeiro e professor da Associação Pestalozzi de Niterói. Tem experiência na área de Design Gráfico, atuando principalmente nos seguintes temas: ilustração editorial, design gráfico e design da informação. Sua dissertação no Mestrado da ESDI/UERJ enfoca a Infografia jornalística contemporânea.

rcunhalima@gmail.com 